\title{
Effects of Heat Stress on Gut Microbiome in Rats
}

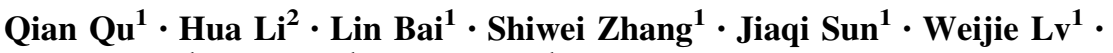 \\ Chunxin $\mathrm{Ye}^{1} \cdot \mathrm{Cui}_{\mathrm{Liu}^{1}} \cdot$ Dayou Shi $^{1}$ (D)
}

Received: 7 March 2021 / Accepted: 19 May 2021/Published online: 29 May 2021

(C) The Author(s) 2021

\begin{abstract}
Gut microbiome, as the largest and most important micro-ecosystem, plays a critical role in health. The purpose of this study was to evaluate whether heat stress modulates the composition and diversity of the gut microbiome in rats. The heat stress model was prepared in rats with the heating temperature maintained at $35-38^{\circ} \mathrm{C}$. Cecum contents were collected after heat stress for $3 \mathrm{~h}$ and days 1, 3 and 7. Total DNA was extracted for $16 \mathrm{~S}$ rRNA sequencing and analysis of intestinal microbiome composition and diversity. The study showed that the composition of the intestinal microbiome of heat stress group was changed. And the heat stress modulated key phylotypes of gut microbiota at the level of phylum and genus. In particular, the genus of Lactobacillus and Bacteroides were significantly reduced, whereas the Oscillospira and Clostridium were increased by heat stress. Meanwhile, the rats under the heat stress encountered the change in carbohydrate metabolism, amino acid metabolism, and membrane transport to defense against stress. Taken together, the composition and structure of gut microbiome were affected by heat stress and some key phylotypes were also significantly altered. We conclude that the heat stress could impact multiple biological functions, via altering the gut microbiome.
\end{abstract}

Cui Liu

liuc@scau.edu.cn

$\bowtie$ Dayou Shi

shidayou@scau.edu.cn

1 College of Veterinary Medicine, South China Agricultural University, Guangzhou 510642, People's Republic of China

2 The Second Affiliated Hospital of Guangzhou Medical University, Guangzhou 510260, People's Republic of China
Keywords Gut microbiome - Heat stress - Metabolism · Rats

$\begin{array}{ll}\text { Abbreviations } \\ \text { HS } & \text { Heat stress } \\ \text { Con } & \text { Control } \\ \text { RT } & \text { Rectal temperature } \\ \text { WBC } & \text { White blood cell } \\ \text { GLU } & \text { Glucose } \\ \text { PD } & \text { Phylogenetic diversity } \\ \text { PCoA } & \text { Principal coordinate analysis } \\ \text { OUT } & \text { Operational taxonomic units } \\ \text { KEGG } & \text { Kyoto, Encyclopedia of Genes and Genomes }\end{array}$

\section{Introduction}

Heat stress resulting from elevated ambient temperature is considered to be one of the most important environmental stresses exerting deleterious effects on homeostasis and severe systemic inflammatory response [1-3]. Heatinduced multiple negative effects on physiological, immune function, central nervous system, gut microbiota and reproductive functions [4-7]. The heat exposure to mice also causes changes in epithelial barrier dysfunction and cell structure, which is the key to colonize gut microbiota [8-10]. Heat stress can cause heatstroke, which is characterized by hyperthermia and central nervous system dysfunction [11]. Under stress, a reduction in intestinal villus height, an increase in crypt depth, and the change of intestinal villus can lead to the weakening of the intestinal absorption and the dysbiosis of the intestinal microflora 
$[9,12,13]$. Over the past few decades, the mechanism of heat stress is considered to be caused by the disorder of central nervous system, not by peripheral organs. And the understanding of intestinal function also focuses on the digestion and absorption of nutrients [14-17].

Microbiota inhabiting the mucosal surface of the animal skin, mouth, gastrointestinal tract and other organs is considered as the largest and most important microecosystem. Gut microbiota residing in the digestive tracts of humans and other animals is the largest and complex community of microorganisms. Gut microbiome play diverse roles in animal and human physiology, including digestion of fiber, starch [18]; degradation of carbohydrate fermentation to produce lactic acid, short chain fatty acids, and other metabolites [19, 20]; synthesize certain vitamins (e.g., B1, B2, B12, VK, and folic acid) [21]; modulate immune system and functions [22, 23]; influence intestinal epithelial permeability [24, 25]; and prevent infections from other pathogens [26]. In addition, emerging evidence suggests that the gut microbiome also regulates brain development and behavior [27-29]. Studies have reported the change in the response of germ-free rats to stress, an abnormality in the hypothalamic pituitary adrenal axis adjustment, and the decrease in the pain caused by inflammation [30, 31]. This study mainly discusses the changes of heat stress on gut microbiome in rats and then provides a new possible mechanism of heat stress leading to inflammatory response and nervous system disorders.

\section{Material and Methods}

\section{Animals}

All experimental procedures in this study were approved by the Animal Ethics Committee of the South China Agricultural University (Guangzhou, China). The care and use of the animals were carried out under the Guidelines for Animal Experiments of the South China Agricultural University, and all efforts were made to minimize the number of animals, suffering, and to maximize their wellbeing (permit number: 2014321, Guangzhou, China). All procedures involving animals throughout the experiments were conducted in strict accordance with the Chinese legislation on the use and care of laboratory animals.

Seven-week-old male-specific pathogen-free (SPF) Wistar rats $(180 \pm 10 \mathrm{~g}$, purchased from the Center of Experimental Animals of Southern Medical University, approval number: 44002100005777) were housed under standard conditions $\left(22 \pm 0.5{ }^{\circ} \mathrm{C}, 50 \pm 5 \%\right.$ humidity, and a $12 \mathrm{~h}$ light/12 $\mathrm{h}$ dark cycle) and maintained with free access to a standard laboratory pellet diet and water.

\section{Experimental Design In Vivo}

Forty adult Wistar male rats were randomly divided into 2 groups with 20 rats in each group: heat stress group (HS) for which the heater temperature is maintained at $35-38{ }^{\circ} \mathrm{C}$ and humidity values at 50 to $60 \%$, and the control group is maintained at a temperature of $24-26{ }^{\circ} \mathrm{C}$ with free access of drinking water and food for 7 days. The rectal temperature was recorded and the contents in cecum from 5 rats were collected after euthanasia at $3 \mathrm{~h}$ and day 1, 3 and 7 . And the blood was drawn from the abdominal aorta, and the resulting serum was used to measure the circulating level of white blood cell (WBC) and glucose (GLU) after clotting at day 7. All samples were stored in $-80{ }^{\circ} \mathrm{C}$ freezer until analysis. In this study, all rats were euthanized by $30 \mathrm{mg} / \mathrm{kg}$ pentobarbital sodium and cervical vertebra dislocation.

\section{Bioinformatics and Statistical Analyses}

Each rat cecum contents were used to extract total DNA for $16 \mathrm{~S}$ rRNA sequencing and analysis of cecum intestinal microbiome. Then Illumina Miseq reads were analysed using FLASH software. Briefly, paired-read pairs were assembled into contigs that contained the V3-V4 Tags of $16 \mathrm{~S}$ rRNA [32]. All Tags need a stringent quality control processing. Any Tags with ambiguous base and shorter than $200 \mathrm{bp}$ were culled. Identical or duplicate sequences were merged. Chimera sequences were checked and removed using usearch61. According to the similarity of sequences, Tags were clustered to (OTUs) [33]. OTUs were calculated at a distance of 0.03 , using the UCLUST [34]. Alpha diversity includes Chaol and Shannon index and rarefaction curves. The beta diversity analysis of PCoA based on Bray-Curtis was calculated by the weighted and unweighted Unifrac [35]. $\mathrm{R}$ was used to visualize the abundance of the bacterial taxonomic composition. Community function prediction is based on the KEGG database. The bar graph of the genus was produced with GraphPad Prism 5 software. The significance of variance was analysed by one-way ANOVA. And *represents $P<0.05$ and **represents $P<0.01$.

\section{Results}

\section{Heat Stress on Rectal Temperature, White Blood Cell and Glucose}

The rectal temperature (RT) was recorded in rats at $3 \mathrm{~h}$ and day 1, 3 and 7 (Table 1). There were obvious differences in the RT of rats during the study between the HS group and control group $(P<0.01)$. The circulating level of WBC 
Table 1 The effect of heat stress on rectal temperature

\begin{tabular}{llllll}
\hline Index & Group & $3 \mathrm{~h}$ & 1 day & 3 days & 7 days \\
\hline RT $\left({ }^{\circ} \mathrm{C}\right)$ & HS & $39.65 \pm 0.06^{* *}$ & $38.52 \pm 0.04^{* *}$ & $39.54 \pm 0.14^{* *}$ & $39.00 \pm 0.24^{* *}$ \\
& Control & $37.63 \pm 0.29$ & $37.00 \pm 0.09$ & $37.67 \pm 0.12$ & $37.78 \pm 0.07$ \\
\hline
\end{tabular}

*Represents $p<0.05$ and ${ }^{* *}$ represents $p<0.01$ compared to the Con group and GLU was also measured on day 7 (Table 2). The level of WBC and GLU in the HS group weas markedly increased by heat stress on day 7 . These data suggested that the model of heat stress was successfully established in this study.

\section{The Effects of Heat Stress on Alpha Diversity Index}

The results on Alpha diversity index of the gut microbiota in rats showed difference between the two groups (Table 3). After heat stress for 3 and 7 days, the Chao 1 index of HS group was significantly decreased than that of the control group. The phylogenetic diversity (PD) whole tree index of the HS group was significantly lower than that of the control group on day 7 and the Shannon index of HS group was significantly lower than that of the control group on $3 \mathrm{~h}$.

\section{The Effect of Heat Stress on the Composition of Gut Microbiome}

The principal coordinate analysis (PCoA) based on the Unifrac distances weighted (Fig. 1) and unweighted (Fig. 2) values was performed to determine the effects of heat stress on gut microbiome composition. In $3 \mathrm{~h}$ and on days 1, 3 and 7, the plot of PCoA were clustered together in the HS group and control group respectively, whereas the scatter points between the HS group and control group showed obvious differences, suggesting that the composition of the gut microbiome changes significantly in each stage by heat stress. These data suggest that the composition of gut microbiota in caecum is markedly changed by heat stress.

Table 2 The effect of heat stress on white blood cell and glucose

\begin{tabular}{llll}
\hline Time point & Group & WBC $\left(\times 10^{9} / \mathrm{L}\right)$ & GLU $(\mathrm{mmol} / \mathrm{L})$ \\
\hline 7 days & HS & $6.52 \pm 0.22^{* *}$ & $7.10 \pm 0.70^{* *}$ \\
& Control & $3.00 \pm 0.48$ & $2.98 \pm 0.56$
\end{tabular}

*Represents $p<0.05$ and $* *$ represents $p<0.01$ compared to the control group

\section{The Community Contributed at the Phylum Level by Heat Stress}

In this study, we used PyNAST software and Greengenes database to compare the known sequences and to compare the relative abundance at the phylum level in all the groups. At the phylum level, the relative abundance and community composition were significantly shifted by heat stress, whereas the dominant bacteria in caeca were Firmicutes and Bacteroidetes in all the groups (Fig. 3). The main phyla of Firmicutes, Bacteroidetes and Verrucomicrobia showed an obvious difference between the two groups. The relative abundance of Firmicutes was increased by heat stress except on day 3. In $3 \mathrm{~h}$ and on day 3 , the phylum of Bacteroidetes was significantly increased than that in the control group, but decreased on days 1 and 7 . The relative abundance of Verrucomicrobia was reduced in the HS group compared to the control group, but increased on day 7. These changed have no time-dependent and may be related to the dynamically changing gut microbiota.

\section{The Changes in Key Phylotypes at the Genus Levels by Heat Stress}

Taxon-based analysis at the genus level showed that the relative abundance of Lactobacillus, Bacteroides, Oscillospira and Clostridium were significantly changed by heat stress (Fig. 4). The relative abundance of Lactobacillus was significantly reduced in the HS group compared to the control group on day $3(P<0.01)$, whereas the relative abundance of Bacteroides was reduced on day 7 $(P<0.01)$. For Oscillospira, the relative abundance was increased by heat stress on day 1,3 and 7 and the Clostridium was also increased in $3 \mathrm{~h}(P<0.05)$ and on day $7(P<0.01)$.

\section{KEGG Community Function Prediction Annotation}

A total of 6909 functional genes were identified and have significant paired genes in the Kyoto, Encyclopedia of Genes and Genomes (KEGG) database. These pathways were divided into five main categories, including metabolic, genetic information processing, environmental information processing, cellular processes, and organismal systems (Fig. 5). Among the 5 functional categories, 35 major KEGG pathways were selected. The changes of 
Table 3 Alpha diversity indexes of the gut microbiota in heat stress rats

\begin{tabular}{lllll}
\hline Time point & Group & Chaol & PD_whole_tree & Shannon \\
\hline $3 \mathrm{~h}$ & HS & $4316.25 \pm 43.14$ & $103.96 \pm 0.49$ & $7.27 \pm 0.15^{*}$ \\
\multirow{3}{*}{1 day } & Control & $5973.33 \pm 264.48$ & $131.50 \pm 3.31$ & $8.13 \pm 0.11$ \\
& HS & $7984.30 \pm 263.59$ & $148.32 \pm 5.11$ & $8.07 \pm 0.04$ \\
3 days & Control & $7003.53 \pm 244.73$ & $148.32 \pm 5.08$ & $7.67 \pm 0.06$ \\
& HS & $6343.86 \pm 229.98^{*}$ & $146.34 \pm 2.49$ & $8.04 \pm 0.02$ \\
7 days & Control & $8101.88 \pm 335.32$ & $163.49 \pm 2.50$ & $8.41 \pm 0.06$ \\
& HS & $4604.57 \pm 215.91^{*}$ & $103.60 \pm 3.22^{*}$ & $7.67 \pm 0.07$ \\
& Control & $6197.48 \pm 192.84$ & $134.86 \pm 2.02$ & $7.88 \pm 0.05$ \\
\hline
\end{tabular}

*Represents $p<0.05$ and **represents $p<0.01$ compared to the control group biological pathways in the HS group mainly concentrated on the four types of pathways: metabolism, genetic information processing, environmental information processing and cellular processes. The HS group was more active in the carbohydrate metabolism, amino acid metabolism, and membrane transport gene expression compared with the control group, indicated that multiple biological functions of the body reaction path were shifted to be more active by heat stress and these changes may be related to the gut microbiome.

\section{Discussion}

Heat stress can lead to the inflammation of the organ, including liver, hypothalamus, and intestinal bleeding, while the mechanism of heat stress based on the nervous system cannot be explained reasonably [5, 14, 36]. Recent Studies demonstrated that heat stress can worsen gut disorders and change the composition of gut microbiota, which may be one of the mechanisms of heat stress [37-39]. The results of this study suggested that the composition and structure of gut microbiota were affected by heat stress and the changes of biological pathways by heat stress may be related to the gut microbiota.

The previous study found that when the ambient temperature exceeds $28{ }^{\circ} \mathrm{C}$, it can lead to the slight rupture and regional edema of the small intestinal (duodenum, jejunum, ileum) villus [10]. In this study, the temperature in our model of heat stress was in agreement with previous studies [1, 40]. And increased the rectal temperature, white blood cell and glucose were observed by heat stress in this study, which is in agreement with other studies of different animals $[12,41]$. Taken together, the model of heat stress was established.

This study was conducted to explore the relationship between the composition of the gut microbiome and heat stress. Heat stress has adverse effects on growth performance, immunity and overall health, but its mechanism remains largely unclear, which may be related to gut microbiota $[42,43]$. In this study, our results showed that the alpha diversity, including Chao1, PD whole tree and Shannon index of gut microbiota in cecum was significantly changed by heat stress. However, there was no significantly change on the alpha diversity index of day 1 , which may be because the gut microbiota is a slow process, and it is consistent with the results of previous studies [7]. In this study, the Chao1 and PD whole tree first increased and then decreased upon heat stress, which may be due to the suddenness of stress stimulation. With the extension of stress time, the adaptation to the stress and gut microbiota of heat stress rats tended to be stable. The Chao1, PD whole tree and Shannon index based on operational taxonomic units (OTU), which is used to estimate the richness and diversity of gut microbiota and predict the number of species, were obvious decreased in HS group compared with the control group, indicating that heat stress can reduce the richness and diversity of gut microbiota. These results are consistent with previous studies that heat stress can change the richness and diversity of gut microbiome [44].

Our results based on PCoA showed that heat stress could modulate the composition of gut microbiome in caecum. Meanwhile, the obvious differences in the relative abundance of bacterial at the phylum and genus level between the HS group and Con group were obtained. Heat stress was previously shown to regulate the diversity of gut microbiota and inhibit the dominant Lactobacillus [45, 46]. And disruptive social, which is another stress, was also shown to reduce the relative abundance of the genus and increase the relative abundance of Clostridium [47].

In the current research, the phyla of Firmicutes and Bacteroidetes were the dominant bacteria and had a significant difference in the caecum of rats by heat stress, which was in agreement with another report, but in the fecal of laying hens [39]. The relative abundance of Bacteroidetes, which contains many beneficial genera, such as Bacteroidetes, was significantly decreased, whereas the Verrumicrobia, including Akkermansia, which can reduce body weight, was increased in the heat stress group, 


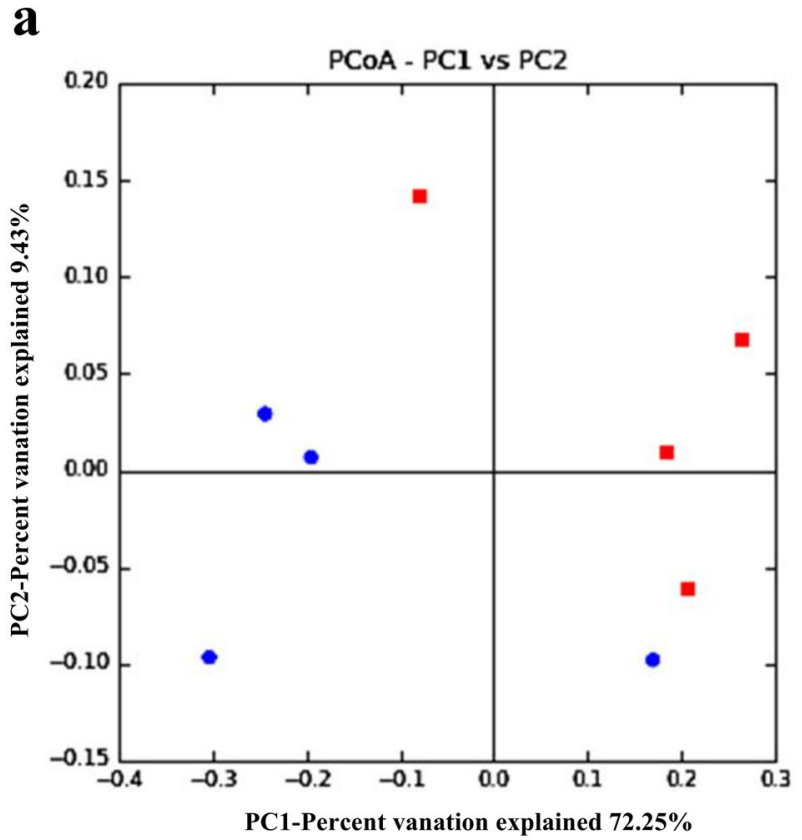

c

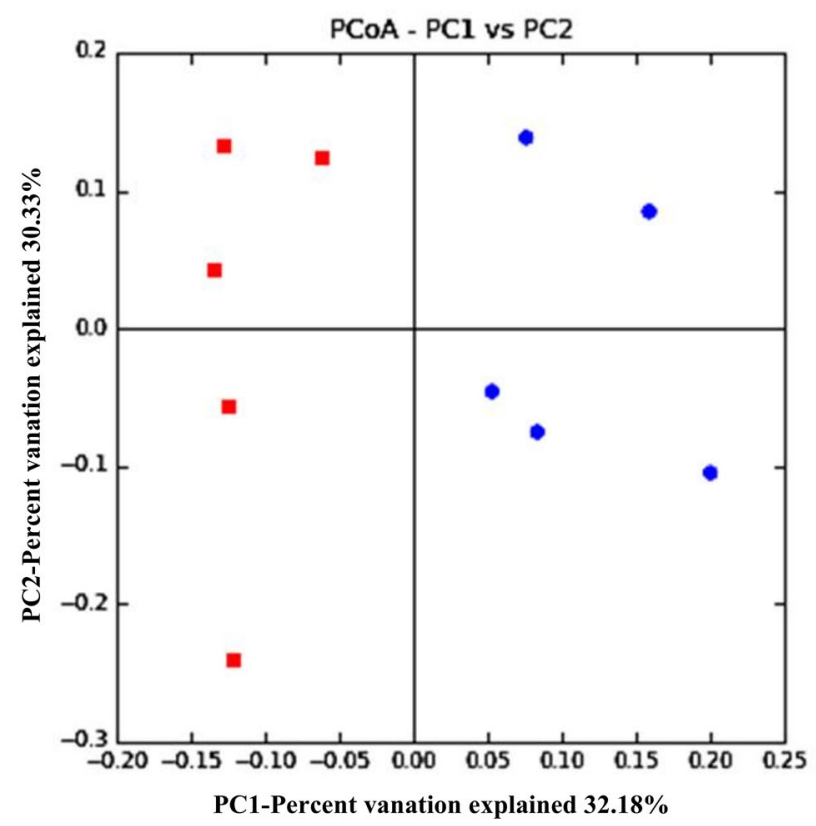

Fig. 1 The composition changes of gut microbiota based on PCoA with weight Unifrac. a The PCoA with weight in $3 \mathrm{~h}$; b the PCoA with weight at day 1 ; $\mathbf{c}$ the PCoA with weight at day 3 ; $\mathbf{d}$ the PCoA

indicating that heat stress can affect the body by gut microbiota. At the genus level, the relative abundance of Lactobacillus and Bacteroides, which were putative beneficial genera, was significantlty reduced, whereas the $O_{s}$ cillospira and Clostridium were increased by heat stress. The finding of Bacteroides is consistent with our previous study on chicken, whereas the result of Oscillospira is contrary [7]. Results of KEGG community function b

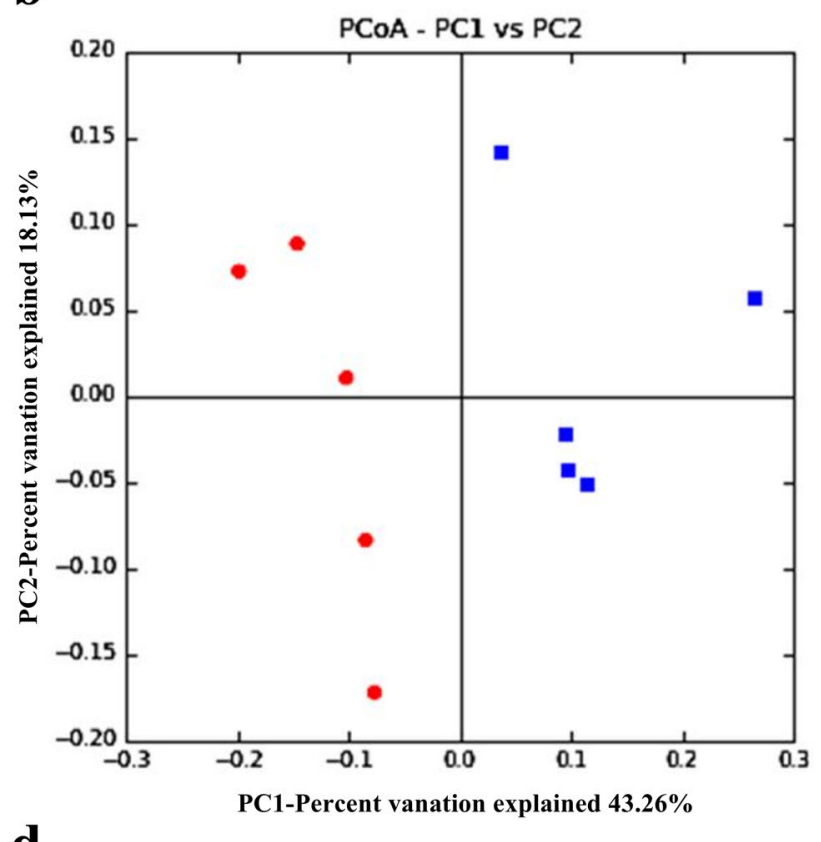

d

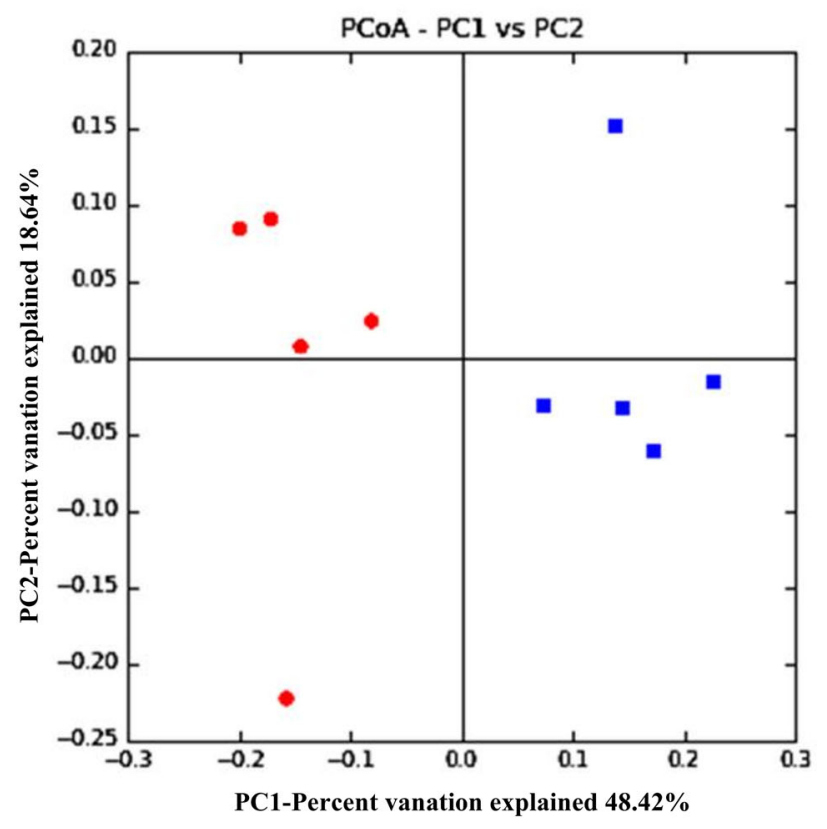

with weight at day 7. PC1and PC2 are the two principal coordinate components. The red plot is the HS group and the blue is the control group

prediction annotation demonstrated that the carbohydrate metabolism, amino acid metabolism, and membrane transport gene expression was more active with heat stress. Lactobacillus produce acetylcholine and $\gamma$-amino butyric acid, Bacteroidetes produce $\gamma$-amino butyric acid and are important in glucose homeostasis of hosts; and Oscillospira are the butyrate producer, which may be the key for the gut microbiome to affect host metabolism and biological 


\section{a}

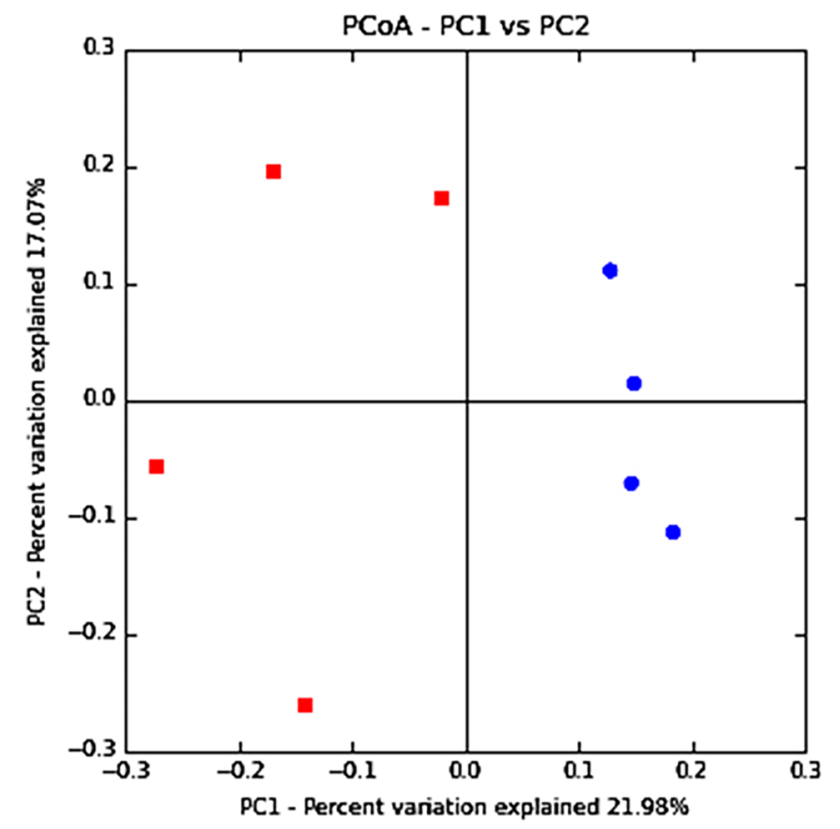

c

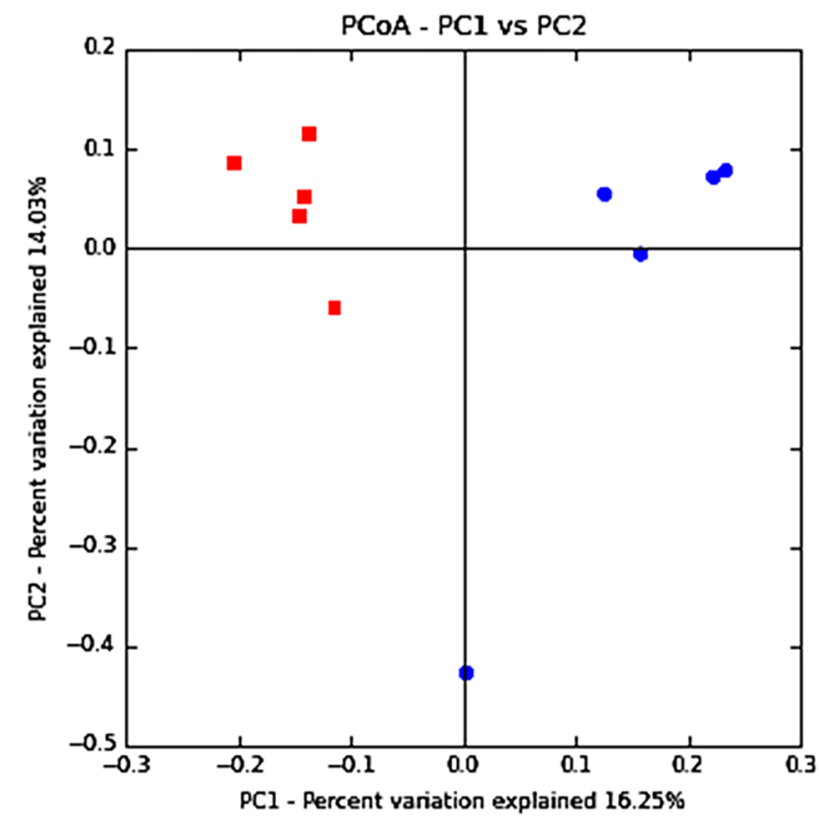

Fig. 2 The composition changes of gut microbiota based on PCoA with unweight Unifrac. a The PCoA with unweight in $3 \mathrm{~h}$; b the PCoA with unweight at day 1 ; $\mathbf{c}$ the PCoA with un weight at day 3 ;

functions [48, 49]. Gut microbiota and their secretions affect the nervous system, and regulate the intestinal motility and sensory afferent signal to the brain [50]. Central nervous system and neuroendocrine activity, in particular stress response, may in turn affect the b

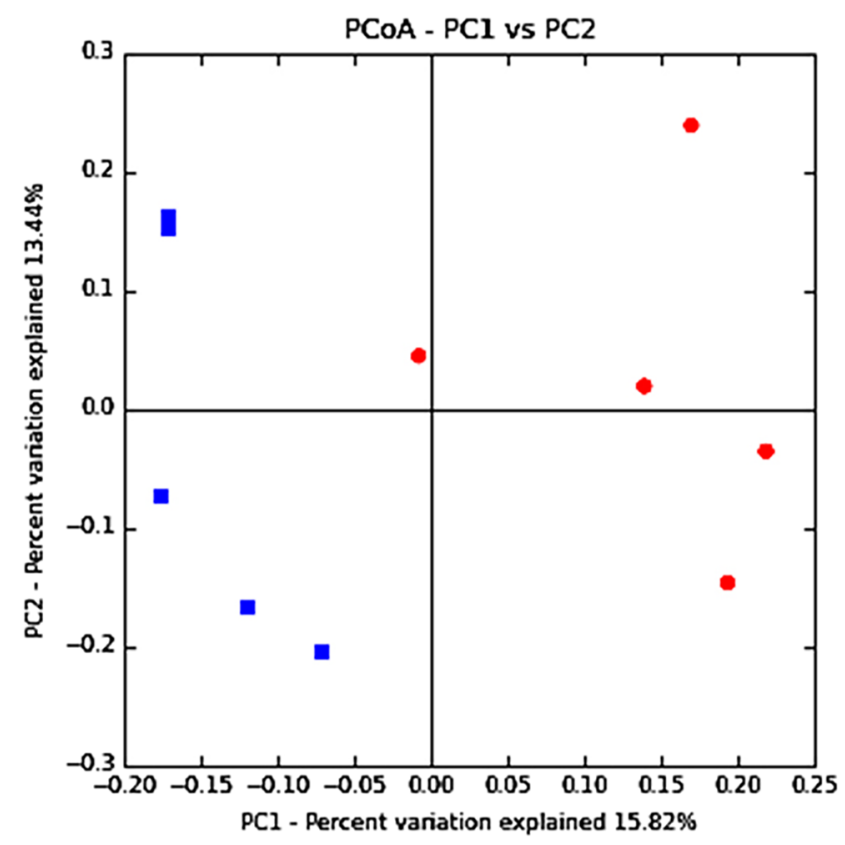

d

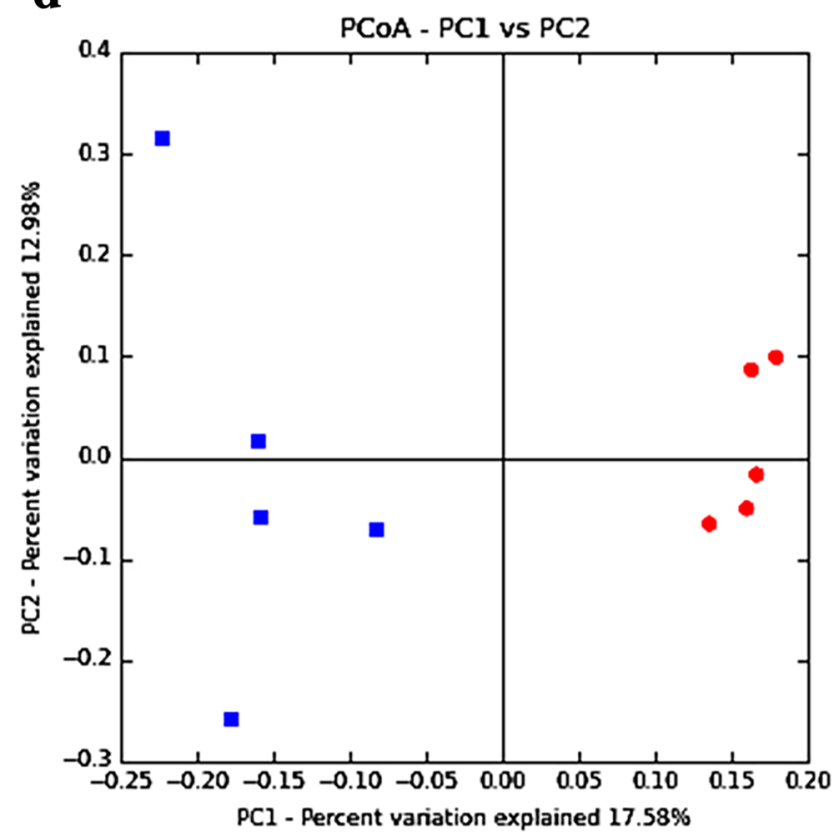

d the PCoA with unweight at day 7. PC1and PC2 are the two principal coordinate components. The red plot is the HS group and the blue is the control group

composition of gut microbiota by changing the abundance of bacterial species and bacterial virulence factors [51]. Diseases can affect the composition of gut microbiome, and then in turn leading to deterioration of the body, which may be a process of circulatory action. 
Fig. 3 The relative abundance of gut microbiome at the phylum level by heat stress in rats. All phyla were defined as 1 , and the proportion of each phylum is defined as percent relative abundance. $\mathrm{H}$ represents HS group and $\mathrm{C}$ represents control group

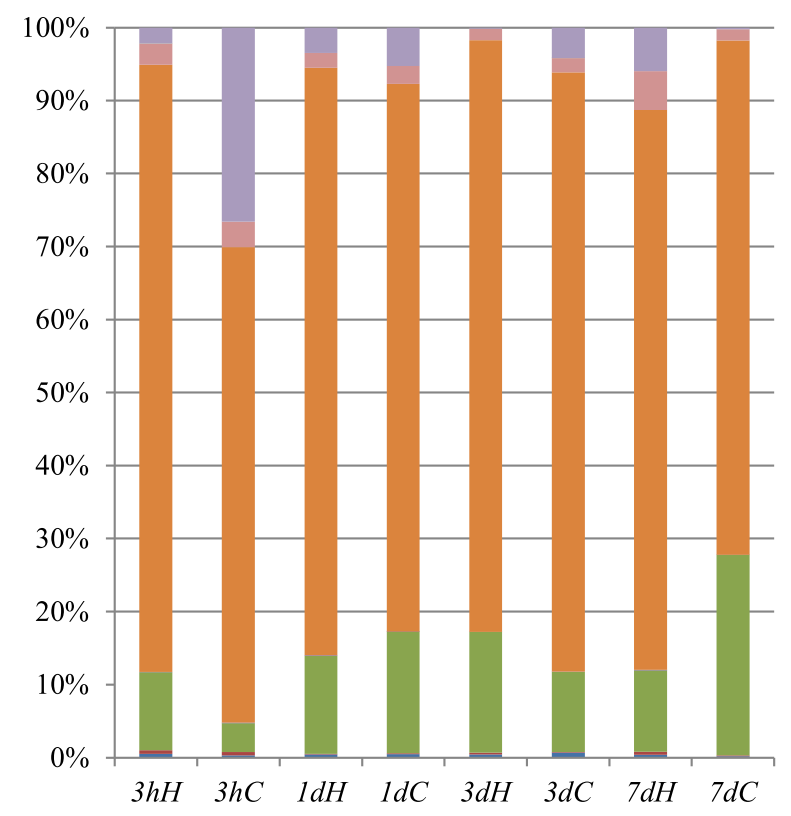

k__Bacteria;p_[Thermi]

$\mathrm{k} \_$B Bacteria; $\_$_Verrucomicro

bia

k__Bacteria;p_t Tenericutes

- k_Bacteria;p_Proteobacteri

a

k__Bacteria;p_OD1

n__Bacteria;

- k_Bacteria;p_Elusimicrobia

- k_Bacteria;p_Cyanobacteri

- k_Bacteria;p__Bacteroidetes a

Percentage of Lactobacillus

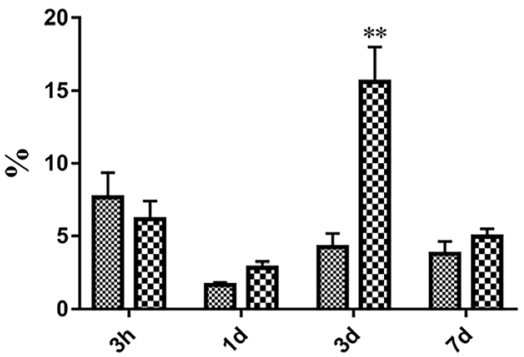

c Percentage of Oscillospira

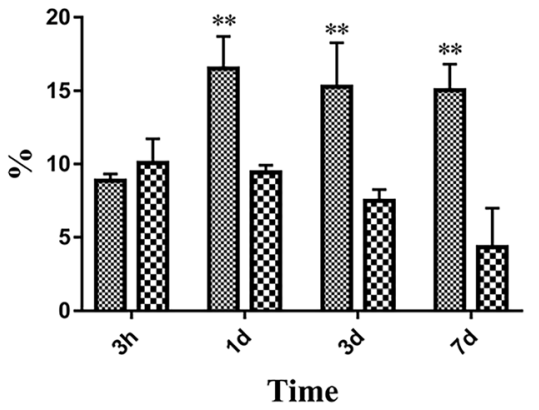

Fig. 4 The relative abundance of gut microbiome at the genus level by heat stress. a The relative abundance of Lactobacillus; b the relative abundance of Bacteroides; $\mathbf{c}$ the relative abundance of b

\section{Percentage of Bacteroides}

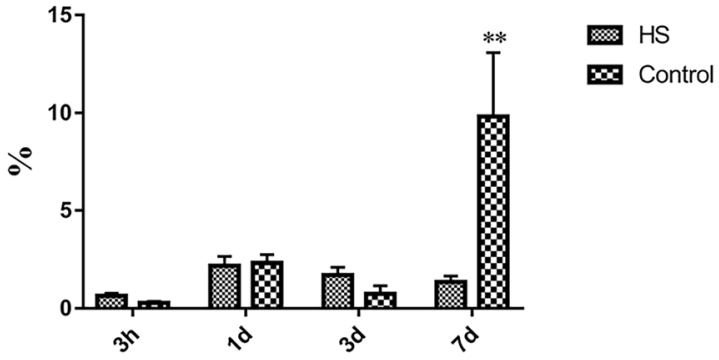

d
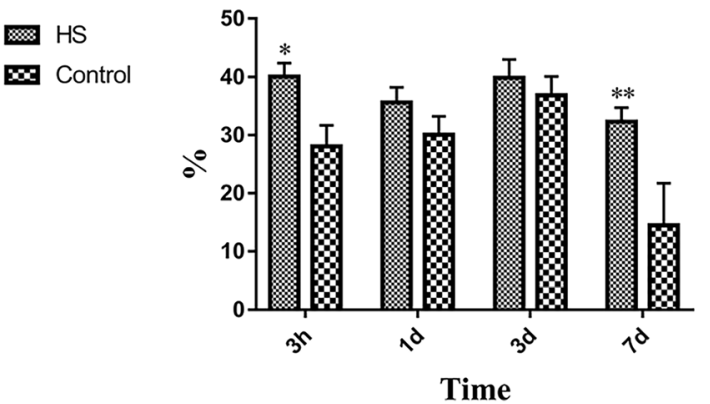

HS

Oscillospira; $\mathbf{d}$ the relative abundance of Clostridum. All genera were defined as 1 , and the proportion of each genus is defined as percent relative abundance 


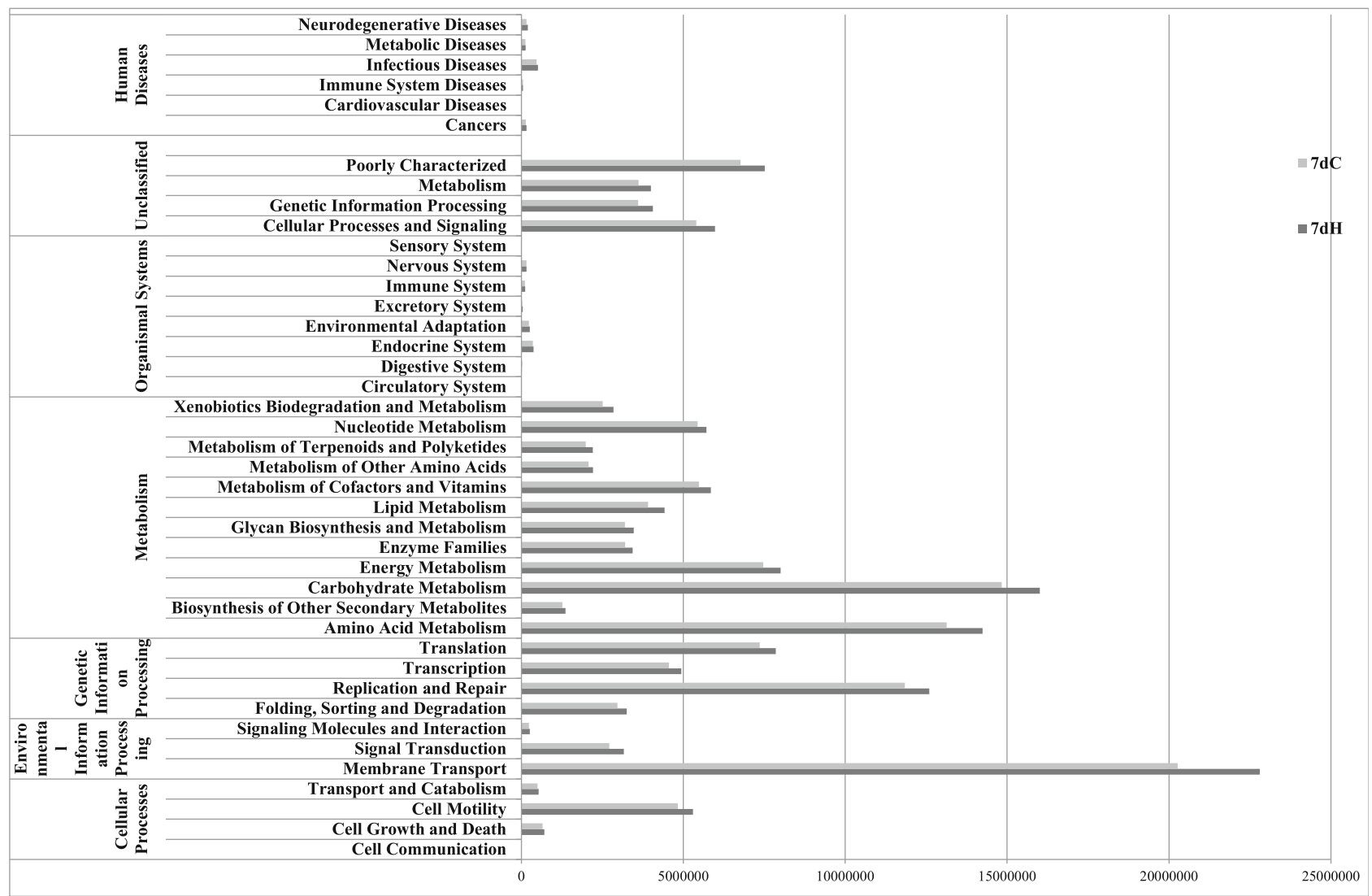

Fig. 5 The KEGG community function prediction annotation by heat stress. $7 \mathrm{dH}$ is the HS group and $7 \mathrm{dC}$ is the control group at day 7

\section{Conclusions}

In conclusion, our results showed that the structure of gut microbiome in rats was altered by heat stress. Particularly, the key genera of Lactobacillus, Bacteroides, Oscillospira and Clostridium, which can produce metabolites, were changed by heat stress. Consequently, based on KEGG, multiple biological functions of the body reaction path were regulated. Taken together, one of the mechanisms of heat stress may be the altered gut microbiota, which may lead to the change of metabolism, and then affect the biological function and nervous system. Future research will be needed to understand the role of metabolites produced by gut microbiome in the brain gut axis.

Acknowledgements We thank the Experimental Animals Center of Southern Medical University (Guangzhou, China) for providing experimental animals. Thanks to Shanghai Personal Biotechnology Limited Company for the analysis of data.

Authors' contributions DS and CL conceived and designed the experiments. QQ, HL, LB, SJ performed the experiments, collected and analyzed the data. QQ wrote the article and SG, WL, SZ, CY revised the article. All authors read and approved the final manuscript.
Funding This study was funded by the National Natural Science Foundation of China (Grant Nos. 31672594, 31602096).

Availability of data and materials All data generated or analysed during this study are included in this published article.

Code availability Not applicable.

\section{Declarations}

Conflict of interest The authors declare that they have no conflict of interest.

Ethics approval All experimental procedures used in this study were approved by the Animal Ethics Committee of the South China Agricultural University (Guangzhou, China). The care and use of all animals were performed according to the Guidelines for Animal Experiments of the South China Agricultural University.

Consent to participate Not applicable.

Consent for publication Not applicable.

Open Access This article is licensed under a Creative Commons Attribution 4.0 International License, which permits use, sharing, adaptation, distribution and reproduction in any medium or format, as long as you give appropriate credit to the original author(s) and the source, provide a link to the Creative Commons licence, and indicate if changes were made. The images or other third party material in this article are included in the article's Creative Commons licence, unless 
indicated otherwise in a credit line to the material. If material is not included in the article's Creative Commons licence and your intended use is not permitted by statutory regulation or exceeds the permitted use, you will need to obtain permission directly from the copyright holder. To view a copy of this licence, visit http://creativecommons. org/licenses/by/4.0/.

\section{References}

1. Lan R, Li S, Chang Q, Zhao Z (2019) Chitosanoligosaccharides protect Sprague Dawley rats from cyclic heat stress byattenuation of oxidative and inflammation stress. Animals (Basel) 9(12):1074. https://doi.org/10.3390/ani9121074

2. Song JH, Kim KJ, Choi SY, Koh EJ, Park J, Lee BY (2019) Korean ginseng extract ameliorates abnormal immune response through the regulation of inflammatory constituents in Sprague Dawley rat subjected to environmental heat stress. J Ginseng Res 43(2):252-260. https://doi.org/10.1016/j.jgr.2018.02.003

3. Dou J, Montanholi YR, Wang Z, Li Z, Yu Y, Martell JE, Wang YJ, Wang Y (2019) Corticosterone tissue-specific response in Sprague Dawley rats under acute heat stress. J Therm Biol 81:12-19. https://doi.org/10.1016/j.jtherbio.2019.02.004

4. Bai WJ, Jin PJ, Kuang MQ, Wei QW, Shi FX, Davis JS, Mao DG (2017) Temporal regulation of extracellular signal-regulated kinase $1 / 2$ phosphorylation, heat shock protein 70 and activating transcription factor 3 during prostaglandin F-induced luteal regression in pseudopregnant rats following heat stress. Reprod Fertil Dev 29(6):1184-1193. https://doi.org/10.1071/RD15415

5. Chauhan NR, Kapoor M, Singh LP, Gupta RK, Meena RC, Tulsawani R, Nanda S, Singh SB (2017) Heat stress-induced neuroinflammation and aberration in monoamine levels in hypothalamus are associated with temperature dysregulation. Neuroscience 358:79-92. https://doi.org/10.1016/j.neuroscience. 2017.06.023

6. Han J, Shao J, Chen Q, Sun H, Guan L, Li Y, Liu J, Liu H (2019) Transcriptional changes in the hypothalamus, pituitary, and mammary gland underlying decreased lactation performance in mice under heat stress. FASEB J 33(11):12588-12601. https:// doi.org/10.1096/fj.201901045R

7. Shi D, Bai L, Qu Q, Zhou S, Yang M, Guo S, Li Q, Liu C (2019) Impact of gut microbiota structure in heat-stressed broilers. Poult Sci 98(6):2405-2413. https://doi.org/10.3382/ps/pez026

8. He S, Guo Y, Zhao J, Xu X, Song J, Wang N, Liu Q (2019) Ferulicacid protects against heat stress-induced intestinal epithelial barrierdysfunction in IEC-6 cells via the PI3K/Aktmediated Nrf2/HO-1 signalingpathway. Int $\mathrm{J}$ Hyperthermia 35(1):112-121. https://doi.org/10.3382/ps/pez026

9. Burkholder KM, Thompson KL, Einstein ME, Applegate TJ, Patterson JA (2008) Influence of stressors on normal intestinal microbiota, intestinal morphology, and susceptibility to Salmonella enteritidis colonization in broilers. Poult Sci 87(9):1734-1741. https://doi.org/10.3382/ps.2008-00107

10. Quinteiro-Filho WM, Ribeiro A, Ferraz-de-Paula V, Pinheiro ML, Sakai M, Sa LR, Ferreira AJ, Palermo-Neto J (2010) Heat stress impairs performance parameters, induces intestinal injury, and decreases macrophage activity in broiler chickens. Poult Sci 89(9):1905-1914. https://doi.org/10.3382/ps.2010-00812

11. Ji J, Hong X, Su L, Liu Z (2019) Proteomic identification of hippocalcin and its protective role in heatstroke-induced hypothalamic injury in mice. J Cell Physiol 234(4):3775-3789. https://doi.org/10.1002/jcp.27143

12. Abuajamieh M, Kvidera SK, Mayorga EJ, Kaiser A, Lei S, Seibert JT, Horst EA, Sanz Fernandez MV, Ross JW, Selsby JT (2018) The effect of recovery from heat stress on circulating bioenergetics and inflammatory biomarkers. J Anim Sci 96(11):4599-4610. https://doi.org/10.1093/jas/sky345

13. Humam AM, Loh TC, Foo HL, Samsudin AA, Mustapha NM, Zulkifli I, Izuddin WI (2019) Effectsof feeding different postbiotics produced by lactobacillus plantarum on growthperformance, carcass yield, intestinal morphology, gut microbiota composition, immune status, and growth gene expression in broilers under heat stress. Animals (Basel). https://doi.org/10.3390/ani9090644

14. Wang D, Cai M, Wang T, Zhao G, Huang J, Wang H, Qian F, Ho C-T, Wang Y (2018) Theanine supplementation prevents liver injury and heat shock response by normalizing hypothalamicpituitaryadrenal axis hyperactivity in mice subjected to whole body heat stress. J Funct Foods 45:181-189. https://doi.org/10. 1016/j.jff.2018.04.001

15. Li H, Liu Y, Gu Z, Li L, Liu Y, Wang L, Su L (2018) p38 MAPK-MK2 pathway regulates the heat-stress-induced accumulation of reactive oxygen species that mediates apoptotic cell death in glial cells. Oncol Lett 15(1):775-782. https://doi.org/10. 3892/ol.2017.7360

16. Morales A, Gomez T, Villalobos YD, Bernal H, Htoo JK, Gonzalez-Vega JC, Espinoza S, Yanez J, Cervantes M (2020) Dietary protein-bound or free amino acids differently affect intestinal morphology, gene expression of amino acid transporters, and serum amino acids of pigs exposed to heat stress. J Anim Sci. https://doi.org/10.1093/jas/skaa056

17. Al-Zghoul MB, Alliftawi ARS, Saleh KMM, Jaradat ZW (2019) Expression of digestive enzyme and intestinal transporter genes during chronic heat stress in the thermally manipulated broiler chicken. Poult Sci 98(9):4113-4122. https://doi.org/10.3382/ps/ pez249

18. Klingbeil EA, Cawthon C, Kirkland R, de La Serre CB (2019) Potato-resistantstarch supplementation improves microbiota dysbiosis, inflammation, andgut-brain signaling in high fat-fed rats. Nutrients 11(11):2710. https://doi.org/10.3390/nu11112710

19. Mhd Jalil AM, Combet E, Edwards CA, Garcia AL (2019) Effectof beta-glucan and black tea in a functional bread on short chain fatty acidproduction by the gut microbiota in a gut digestion/fermentation model. Int J Environ Res Public Health 16(2):227. https://doi.org/10.3390/ijerph16020227

20. Beaumont M, Portune KJ, Steuer N, Lan A, Cerrudo V, Audebert M, Dumont F, Mancano G, Khodorova N, Andriamihaja M (2017) Quantity and source of dietary protein influence metabolite production by gut microbiota and rectal mucosa gene expression: a randomized, parallel, double-blind trial in overweight humans. Am J Clin Nutr 106(4):1005-1019. https://doi. org/10.3945/ajen.117.158816

21. LeBlanc JG, Milani C, de Giori GS, Sesma F, van Sinderen D, Ventura M (2013) Bacteria as vitamin suppliers to their host: a gut microbiota perspective. Curr Opin Biotechnol 24(2):160-168. https://doi.org/10.1016/j.copbio.2012.08.005

22. Bachem A, Makhlouf C, Binger KJ, de Souza DP, Tull D, Hochheiser K, Whitney PG, Fernandez-Ruiz D, Dahling S, Kastenmuller W (2019) Microbiota-derived short-chain fatty acids promote the memory potential of antigen-activated CD8(+) $\mathrm{T}$ cells. Immunity 51(2):285-297 e285. https://doi.org/10.1016/j. immuni.2019.06.002

23. Bharwani A, Mian MF, Surette MG, Bienenstock J, Forsythe P (2017) Oral treatment with Lactobacillus rhamnosus attenuates behavioural deficits and immune changes in chronic social stress. BMC Med 15(1):7. https://doi.org/10.1186/s12916-016-0771-7

24. Lau E, Marques C, Pestana D, Santoalha M, Carvalho D, Freitas P, Calhau C (2016) The role of I-FABP as a biomarker of intestinal barrier dysfunction driven by gut microbiota changes in obesity. Nutr Metab (Lond) 13:31. https://doi.org/10.1186/ s12986-016-0089-7 
25. Wang JH, Bose S, Kim GC, Hong SU, Kim JH, Kim JE, Kim H (2014) Flos Lonicera ameliorates obesity and associated endotoxemia in rats through modulation of gut permeability and intestinal microbiota. PLoS One 9(1):e86117. https://doi.org/10. 1371/journal.pone.0086117

26. Han Z, Willer T, Li L, Pielsticker C, Rychlik I, Velge P, Kaspers B, Rautenschlein S (2017) Influenceof the gut microbiota composition on Campylobacterjejuni colonization in chickens. Infect Immun 85(11):e00380-17. https://doi.org/10.1128/iai.00380-17

27. Pusceddu MM, El Aidy S, Crispie F, O'Sullivan O, Cotter P, Stanton C, Kelly P, Cryan JF, Dinan TG (2015) N-3 polyunsaturated fatty acids (PUFAs) reverse the impact of early-life stress on the gut microbiota. PLoS ONE 10(10):e0139721. https://doi. org/10.1371/journal.pone.0139721

28. Tarr AJ, Galley JD, Fisher SE, Chichlowski M, Berg BM, Bailey MT (2015) The prebiotics 3'Sialyllactose and 6'Sialyllactose diminish stressor-induced anxiety-like behavior and colonic microbiota alterations: evidence for effects on the gut-brain axis. Brain Behav Immun 50:166-177. https://doi.org/10.1016/j.bbi. 2015.06.025

29. Cryan JF, Dinan TG (2015) More than a gut feeling: the microbiota regulates neurodevelopment and behavior. Neuropsychopharmacology 40(1):241-242. https://doi.org/10.1038/npp. 2014.224

30. Amaral FA, Sachs D, Costa VV, Fagundes CT, Cisalpino D, Cunha TM, Ferreira SH, Cunha FQ, Silva TA, Nicoli JR (2008) Commensal microbiota is fundamental for the development of inflammatory pain. Proc Natl Acad Sci U S A 105(6):2193-2197. https://doi.org/10.1073/pnas.0711891105

31. Sudo N, Chida Y, Aiba Y, Sonoda J, Oyama N, Yu XN, Kubo C, Koga Y (2004) Postnatal microbial colonization programs the hypothalamic-pituitary-adrenal system for stress response in mice. J Physiol 558(Pt 1):263-275. https://doi.org/10.1113/jphy siol.2004.063388

32. Magoc T, Salzberg SL (2011) FLASH: fast length adjustment of short reads to improve genome assemblies. Bioinformatics 27(21):2957-2963. https://doi.org/10.1093/bioinformatics/btr507

33. Huse SM, Welch DM, Morrison HG, Sogin ML (2010) Ironing out the wrinkles in the rare biosphere through improved OTU clustering. Environ Microbiol 12(7):1889-1898. https://doi.org/ 10.1111/j.1462-2920.2010.02193.x

34. Edgar RC (2010) Search and clustering orders of magnitude faster than BLAST. Bioinformatics 26(19):2460-2461. https:// doi.org/10.1093/bioinformatics/btq461

35. Lozupone C, Lladser ME, Knights D, Stombaugh J, Knight R (2011) UniFrac: an effective distance metric for microbial community comparison. ISME J 5(2):169-172. https://doi.org/10. 1038/ismej.2010.133

36. Ahmed RG (2005) Heat stress induced histopathology and pathophysiology of the central nervous system. Int J Dev Neurosci 23(6):549-557. https://doi.org/10.1016/j.ijdevneu.2005.05. 005

37. Koch F, Thom U, Albrecht E, Weikard R, Nolte W, Kuhla B, Kuehn C (2019) Heat stress directly impairs gut integrity and recruits distinct immune cell populations into the bovine intestine. Proc Natl Acad Sci U S A 116(21):10333-10338. https://doi. org/10.1073/pnas.1820130116

38. He J, He Y, Pan D, Cao J, Sun Y, Zeng X (2019) Associationsof gut microbiota with heat stress-induced changes of growth, fat deposition,intestinal morphology, and antioxidant capacity in ducks. Front Microbiol 10:903. https://doi.org/10.3389/fmicb. 2019.00903

39. Zhu L, Liao R, Wu N, Zhu G, Yang C (2019) Heat stress mediates changes in fecal microbiome and functional pathways of laying hens. Appl Microbiol Biotechnol 103(1):461-472. https://doi.org/10.1007/s00253-018-9465-8

40. Bozkaya F, Atli MO, Guzeloglu A, Kayis SA, Yildirim ME, Kurar E, Yilmaz R, Aydilek N (2017) Effects of long-term heat stress and dietary restriction on the expression of genes of steroidogenic pathway and small heat-shock proteins in rat testicular tissue. Andrologia 49(6):e12668. https://doi.org/10.1111/ and.12668

41. Bao JW, Qiang J, Tao YF, Li HX, He J, Xu P, Chen DJ (2018) Responses of blood biochemistry, fatty acid composition and expression of microRNAs to heat stress in genetically improved farmed tilapia (Oreochromis niloticus). J Therm Biol 73:91-97. https://doi.org/10.1016/j.jtherbio.2018.02.007

42. Mashaly MM, Hendricks GL 3rd, Kalama MA, Gehad AE, Abbas AO, Patterson PH (2004) Effect of heat stress on production parameters and immune responses of commercial laying hens. Poult Sci 83(6):889-894. https://doi.org/10.1093/ps/83.6.889

43. Rostagno MH (2020) Effects of heat stress on the gut health of poultry. J Anim Sci 98(4):2405-2413. https://doi.org/10.1093/jas/ skaa090

44. Chen S, Wang J, Peng D, Li G, Chen J, Gu X (2018) Exposure to heat-stress environment affects the physiology, circulation levels of cytokines, and microbiome in dairy cows. Sci Rep 8(1):14606. https://doi.org/10.1038/s41598-018-32886-1

45. Mohammed AA, Jiang S, Jacobs JA, Cheng HW (2019) Effect of a synbiotic supplement on cecal microbial ecology, antioxidant status, and immune response of broiler chickens reared under heat stress. Poult Sci 98(10):4408-4415. https://doi.org/10.3382/ps/ pez246

46. He J, Guo H, Zheng W, Xue Y, Zhao R, Yao W (2019) Heat stress affects fecal microbial and metabolic alterations of primiparous sows during late gestation. J Anim Sci Biotechnol 10:84. https://doi.org/10.1186/s40104-019-0391-0

47. Bailey MT, Dowd SE, Galley JD, Hufnagle AR, Allen RG, Lyte M (2011) Exposure to a social stressor alters the structure of the intestinal microbiota: implications for stressor-induced immunomodulation. Brain Behav Immun 25(3):397-407. https:// doi.org/10.1016/j.bbi.2010.10.023

48. Hsiao EY, McBride SW, Hsien S, Sharon G, Hyde ER, McCue T, Codelli JA, Chow J, Reisman SE, Petrosino JF (2013) Microbiota modulate behavioral and physiological abnormalities associated with neurodevelopmental disorders. Cell 155(7):1451-1463. https://doi.org/10.1016/j.cell.2013.11.024

49. Lyte $M$ (2004) Microbial endocrinology and infectious disease in the 21st century. Trends Microbiol 12(1):14-20. https://doi.org/ 10.1016/j.tim.2003.11.004

50. Forsythe P, Kunze WA, Bienenstock J (2012) On communication between gut microbes and the brain. Curr Opin Gastroenterol 28(6):557-562. https://doi.org/10.1097/mog.0b013e3283572ffa

51. Galland L (2014) The gut microbiome and the brain. J Med Food 17(12):1261-1272. https://doi.org/10.1089/jmf.2014.7000

\section{Publisher's Note}

Springer Nature remains neutral with regard to jurisdictional claims in published maps and institutional affiliations. 